\title{
A cena englobante da prática discursiva político-midiática do governo do estado do Pará: a constituição das instâncias de enunciação da propaganda oficial
}

Diego Michel Nascimento Bezerra*

Fátima Cristina da Costa Pessoa**

\section{Resumo}

Este estudo objetiva expor o funcionamento discursivo da propaganda de governo do estado do Pará por meio da caracterização da cena englobante que articula as condições de emprego dos anúncios dessa esfera de mando político, no período de 2011 a 2014 . Para evidenciar o modo como os sentidos são processados nessa superfície discursiva, constituiu-se um corpus de textos de arquivo que serve de base para o ordenamento da prática de propaganda oficial, os quais incidem diretamente nos anúncios veiculados pela administração pública do Pará sob a gestão de um partido de centro-esquerda. Discute-se a cena englobante (MAINGUENEAU, 2008b, 2013, 2015) que projeta o contexto acional de interação entre sujeitos a partir das competências interdiscursivas implicadas na produção da materialidade simbólica em questão. Argumenta-se sobre a constituição de uma prática de comunicação híbrida que interpela o coenunciador enquanto cidadão-espectador.

Palavras-chave: Cena englobante. Propaganda governamental. Competência interdiscursiva.
* Licenciado em Língua Portuguesa pela UFPA (2006), com especialização em Ensino/aprendizagem do Português como língua materna pela UFPA (2009) e licenciatura plena em Língua Espanhola pela UFPA (2014). Mestrando em Linguística do Programa de Pós-graduação em Letras da UFPA, com pesquisa no âmbito da Análise do Discurso francesa. Trabalhou como professor efetivo de Língua Portuguesa e de Língua Espanhola nas redes municipal e estadual de ensino do Pará. Atualmente, trabalha como professor substituto do curso de Língua Espanhola do Campus de Abaetetuba/UFPA.

* Graduada em Letras e Artes pela Universidade Federal do Pará (1990). Mestra em Letras: Linguística e Teoria Literária pela Universidade Federal do Pará (1997). Doutora em Estudos Linguísticos pela Universidade Federal de Minas Gerais (2004). Atualmente, é Professora Associada da Universidade Federal do Pará, atuando na Faculdade de Letras e no Programa de Pós-Graduação em Letras. Tem experiência na área de Linguística, com ênfase em Teoria e Análise Linguística, especificamente em Análise do Discurso, atuando principalmente na interface linguagem, discurso e trabalho.

Data de submissão: mar. 2016 - Data de aceite: maio 2016 http://dx.doi.org/10.5335/rdes.v12i1.5847 


\section{Introdução}

O sistema de restrições semânticas, conforme proposto por Maingueneau (2008a), desdobra-se em noções que procuram dar conta dos processos de materialização das superfícies discursivas. Desenhou-se, com base na abordagem adotada por este autor, um percurso de análise dedicado a verificar a relação entre trajetos de sentido e os mecanismos de textualização dos discursos. Sob esta perspectiva, a noção de cena englobante, um dos aspectos do modo de enunciação dos discursos, tem sido recuperada em análises discursivas, objetivando apontar o recorte de um setor da atividade social no qual os enunciados se inscrevem.

Buscando contribuir com a produtividade da agenda de pesquisa sobre o funcionamento das práticas discursivas sob o viés da análise do discurso $(\mathrm{AD})$ francesa, postula-se, neste trabalho, que a cena englobante da propaganda instaurada pelo dizer das esferas administrativas de governo condiciona a interpretação de anúncios de governo pelo cidadão por um regime de estado marcado ideologicamente por um posicionamento democrático e social, elaborados e difundidos durante a gestão do Partido da Social Democracia Brasileira (PSDB) no governo do estado do Pará.

Os procedimentos de análise ancoram-se na interface estabelecida entre a superfície textual que se estabeleceu e as comunidades de enunciadores que lhe estão implicadas, recompondo-se, neste prospecto, o quadro das qualificações requeridas para falar legitimamente sobre a atividade política de governo em um espaço público deslocado, em grande medida, para a esfera midiática.

Nas linhas subsequentes deste artigo, são apresentadas as considerações teóricas de Maingueneau (2008b) sobre a projeção da cena englobante no processo de tomada da palavra pelo sujeito localizado institucionalmente, considerando-se sua relevância na formatação do quadro cênico da enunciação que decorre das restrições semânticas do discurso. Em seguida, os parâmetros para a composição do corpus de quatro textos que, considerados pela perspectiva interdiscursiva, relacionam-se diretamente ao ordenamento da prática discursiva político-midiática do governo do estado do Pará. Na continuidade, os textos são frequentados analiticamente com vistas a validar a operacionalidade do conceito de cena englobante por meio da observação das competências que estabelecem a relação entre enunciadores e coenunciadores na comunicação governamental da referida gestão.

\section{A noção de cena englobante: implicações teóricas}

A cena englobante é postulada por Maingueneau (2008b, 2013, 2015) como uma das circunstâncias discursivas que engendra cada enunciado, cada tomada de palavra pelo sujeito localizado ins- 
titucionalmente. Essa cena tem a ver expressamente com as determinações do campo de discurso em que o enunciador/locutor e seu produto simbólico se localizam. Ela envolve a atividade de linguagem da instância enunciativa em dada prática discursiva.

De modo geral, se a cena de enunciação é constitutiva do discurso, como afirmam Charaudeau e Maingueneau (2012), a locução de um texto resulta das condições impostas implicitamente pelas redes semânticas dos discursos que dinamizam a sociedade. A cena englobante de um enunciado decorre, portanto, da "[atribuição] de um estatuto pragmático ao tipo de discurso a que pertence um texto" (CHARAUDEAU; MAINGUENEAU, 2012, p. 96). Efetiva-se, por meio dela, a atualização do discurso pelo sujeito mediante o processo de alteridade responsiva em cada inscrição enunciativa. Posto desta forma, a cena englobante é a circunstância discursiva que, segundo Maingueneau, permite ao leitor situar um texto em um campo discursivo para poder interpretá-lo, atribuir-lhe sentidos. Assim,

[...] quando [se recebe] um folheto na rua, [deve-se] determinar a que título ele nos interpela, se ele é resultante do discurso político, publicitário, religioso (MAINGUENEAU, 2015, p. 118).

Evidencia-se, por meio da cena englobante, a própria competência interdiscursiva dos sujeitos que, dispostos no quadro da enunciação, adaptam-se às coerções impostas pelo discurso. O sujeito, ao transitar pelas comunidades dis- cursivas, relaciona-se com o que Ducrot (1987) define como catálogo de relações inter-humanas da língua. No nível da cena englobante, verifica-se o reconhecimento pelos sujeitos da circunscrição dos enunciados a dado campo discursivo.

Para delinear um modelo conceitual que descreva adequadamente a progressão enunciativa em dado contexto acional, recorre-se à competência interdiscursiva como ideia segundo a qual o sujeito reconhece, por meio de um saber mais ou menos consciente, certas regularidades do "terreno" discursivo do qual provêm os enunciados com os quais se defronta no cotidiano. Desse modo, a cena englobante não é apenas um elemento isolável do dispositivo da enunciação, mas parte integrante de um sistema regido por restrições semânticas que definem os planos constitutivos do discurso. Trata-se do processo de constituição do enunciado pelas restrições da grade semântica de uma zona de regularidades discursiva. Essa realidade permite que as materialidades sígnicas sejam interpretáveis, avocando sentidos de ordem política, religiosa, literária, etc.

Para o estudioso do discurso (diferentemente do leitor usual de textos), não se trata de indicar intuitivamente o tipo de discurso a que pertence a configuração do enunciado, mas de fundamentar e justificar explicitamente a análise da cena englobante na interdiscursividade relativa à configuração de dado corpus, explorando até as últimas consequências a dimensão do espaço discursivo que 
"deve resultar apenas de hipóteses fundadas sobre um conhecimento de textos e um saber histórico" (MAINGUENEAU, 1997, p. 117).

O investimento em análises sobre a cena englobante de uma seleção de textos enriquece objetivamente a interpretação dos sentidos tributáveis a eles em decorrência de sua aparição na cadeia da enunciação. Sob tal ângulo, observa-se que o estatuto semântico do discurso define as características de uma publicação e seu estatuto pragmático ao projetar a cena englobante por meio da qual se pode interpretar um enunciado. Diante da operacionalidade dessa noção em particular, tem-se integradas, assim, as propriedades específicas ligadas aos participantes e ao seu modo de enunciação, que se apoiam sob uma competência subjetiva histórico-ideológica que define o contexto acional de cada enunciado. Quando se fala em cena englobante como um dos níveis de progressão do enunciado, fala-se igualmente da vertente pragmática do discurso relacionada às condições de legitimação do dizer. Ou seja, tal cena constitui-se, mediante as restrições semânticas de um discurso, como uma condição legitimadora do enunciado.

A cena englobante, portanto, é resultante da competência interdiscursiva dos sujeitos, que imersos em uma conjuntura socio-histórica transitam por diversas comunidades discursivas. Ela vincula-se à capacidade de interpretar os sentidos de cada enunciado segundo as redes de memória que são tecidas no espaço social. Poder-se-ia considerá-la como uma condição indispensável que subjaz ao sentido dos enunciados, assinalando seu lugar de inscrição social e discursiva.

\section{Metodologia}

Justificada nas linhas precedentes a postura teórica que encaminhará a análise da cena englobante da prática político-midiática do governo do estado do Pará, duas dificuldades imediatas emergem ao se considerar a produção dos anúncios da propaganda oficial: a) sua origem enquanto superfície textual condicionada por uma cena englobante tensionada entre diferentes lugares de produção discursiva; b) a maneira pela qual se pode descrever analiticamente os anúncios aí produzidos em relação a este lugar de intersecção.

Conforme modelo de análise proposto por Maingueneau (2008a), em que não há interrupção ou mesmo sucessão de planos discursivos, o acesso à interdiscursividade que condiciona certa materialidade sígnica recortada em função de uma problemática discursiva permite resolver as dificuldades elencadas no parágrafo anterior acerca das bases sob as quais se constitui a cena englobante da enunciação. Reafirma-se no prospecto de análise deste trabalho princípios e técnicas que regulam a atividade hermenêutica em $\mathrm{AD}$, bem como o fato de que a identificação das regularidades de um discurso não tem nada de evidente. Assim, não sendo dada aprioristicamente, 
uma taxonomia discursiva resulta de escolhas e hipóteses do pesquisador, como tem sustentado Maingueneau (2008a).

A observação do contexto acional dos anúncios da propaganda de governo do estado do Pará aponta para uma prática discursiva tensionada entre dois mundos de sentidos que se entrecruzam harmoniosamente no espaço público contemporâneo, isto é, a associação entre um dizer-fazer da política e um dizer-fazer da propaganda. O investimento na identificação da cena englobante que articula esses textos midiáticos abre espaço para que se se possa inferir acerca da heterogeneidade constitutiva da qual se descentra a superfície da propaganda de governo do estado do Pará. Para tanto, assume-se como corpus as seguintes materialidades (enquanto unidades de sentido) da conjuntura histórico-social mais recente que legitimam as condições de enunciabilidade da propaganda de governo brasileira, bem como favorecem a interpretação da cena englobante da propaganda oficial paraense enquanto prática dotada de corpo institucional:

a) Lei $\mathrm{n}^{\circ} 12.232$, de 29 de abril de 2010 , sobre as normas gerais para licitação e contratação pela administração pública de serviços de agências de propaganda;

b) Lei $\mathrm{n}^{\mathrm{o}} 4.680$, de 18 de junho de 1965 , que versa sobre o reconhecimento legal das atividades da propaganda enquanto setor profissional autônomo;

c) Normas-padrão da atividade publicitária de 1998, acordado por conselho executivo formado por entidades do setor midiático brasileiro;

d) Programa do Partido da Social Democracia Brasileira - PSDB.

Pode-se dizer, com base em uma perspectiva histórico-ideológica, que a dispersão dos anúncios da propaganda de governo do estado do Pará no período de 2011 a 2014 (período em que a máquina administrativa da referida esfera executiva era administrada pelo PSDB) está efetivamente relacionada a uma memória discursiva que engendra as possibilidades do que pode e deve ser dito às pessoas afetadas pelas ações da administração pública.

Cabe comentar quanto à seleção desses quatro textos que não se tem por objetivo realizar um juízo de valor acerca da validade dos sentidos impressos neles ao longo do tempo, mas de asseverar a realidade interdiscursiva que está na base da construção da cena englobante que articula a superfície textual da propaganda oficial do estado do Pará. Sob essa tutela, é possível considerar mediante tais relações interdiscursivas que a constituição da prática discursiva político-midiática de qualquer configuração de governo "pode deixar-se descrever em termos de operações regulares sobre formações discursivas já existentes" (MAINGUENEAU, 2008a, p. 34).

É importante mencionar que seria muito conveniente identificar a cena englobante que articula anúncios de propaganda oficial, de modo intuitivo, no eixo restrito da comunicação políti- 
ca conforme definida por Rego (1985). Entretanto, o contraste do conceito de prática discursiva adotado neste trabalho com textos de propaganda oficial levanta dificuldades de ordem discursiva que afastam a apreensão da cena englobante enquanto estatuto pragmático relativamente estável de um único "tipo de discurso", dada a fragmentação do espaço social em múltiplos setores de atividades interdependentes, como se constata em Maingueneau (2010) e em Charaudeau (2013a, 2013b). Portanto, a cena englobante da propaganda de governo não é de fácil caracterização, dado que setores de atividades diferentes se coadunam para a produção desse tipo de materialidade. Essa dificuldade pode ainda ser aprofundada quando se pensa a constituição da cena englobante da propaganda de governo alinhada a distintos quadros de enunciadores que se instituem a partir da ação do interdiscurso implicado no processo de qualificação dos sujeitos das práticas discursivas da política e da propaganda.

Para dar concretude à interpretação da cena englobante, faz-se necessário, desta forma, relacionar a superfície textual da propaganda oficial às determinações de uma rede de memória e de trajeto de sentidos projetados por meio de hipóteses de uma possível recepção em função de uma competência interdiscursiva que leva um sujeito a determinar a que título cada anúncio do governo do estado do Pará o interpela.
A cena englobante da propaganda do governo do estado do Pará: a constituição de uma superfície simbólica articulada por sentidos constituídos no campo político-midiático

Para iniciar esta reflexão, parte-se da célebre fórmula de que "não há discurso sem sujeito. E não há sujeito sem ideologia" (ORLANDI, 2012, p. 47). Ao se considerar o corpus desta pesquisa diante de tal máxima, entende-se que o processo de subjetivação enunciativa da propaganda do governo do estado do Pará envolve, notadamente, duas competências discursivas: a da política institucional e a da propaganda. Nesse ponto de interconexão discursiva, emerge a posição de um sujeito da enunciação que interpela seus enunciatários como cidadãos e espectadores. $\mathrm{O}$ sujeito da prática de propaganda oficial do governo do Pará assume uma atitude linguageira singular, cindida entre as técnicas de persuasão de massa e dos processos de informação cidadã.

Posto isso, faz-se necessário investir no reconhecimento do espaço de discurso por meio do qual esse sujeito se constitui e se dispersa na superfície textual que, na reflexão de Orlandi (2012), é condicionada historicamente. Ele virá a ser aquilo que as condições semânticas 
permitirem que ele seja discursivamente. Assim sendo, pode-se retomar o que Maingueneau (2010) discute sobre a diversidade de práticas discursivas de nossa sociedade: é preciso observar seu modo de pertencimento ao universo social e a partir daí vislumbrar explicações acerca do sujeito que vem à tona por meio da linguagem implicada ideologicamente. $\mathrm{O}$ modo de pertencimento social de uma prática discursiva ajuda a entender a natureza do sujeito que surge na encruzilhada entre política e propaganda no estágio de desenvolvimento das práticas discursivas que dinamizam atualmente a sociedade.

\section{Delimitações discursivas das práticas de propaganda}

O primeiro texto que compõe o corpus de análise constitui-se por um conjunto de normas para disciplinar a associação entre esferas do poder público e agências de propaganda. Nesse documento, indica-se implicitamente o reconhecimento, pelo poder público, da interdependência e autonomia dos setores implicados na construção da prática da propaganda de governo. Nessa direção, tal prática de propaganda pode ser caracterizada como esporádica e fugaz em decorrência das alternâncias operadas em tal lugar de discursividade: mudanças de partidos com perfis ideológicos opostos, assim como mudança de agências de propaganda em função da aprovação de seus briefing mediante processo licitatório. Esse reconhecimento implícito pode ser

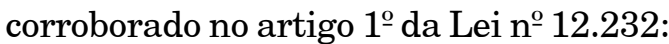

\section{(1) Lei no 12.232}

Art. $1^{0}$ Esta Lei estabelece normas gerais sobre licitações e contratações pela administração pública de serviços de publicidade prestados necessariamente por intermédio de agência de propaganda, no âmbito da União, dos Estados, Distrito Federal e dos Municípios (BRASIL, 2010, p. 1).

Nota-se que a voz oficial refere-se às práticas de propaganda como um setor de atividade bem delimitado, que se estrutura originalmente fora das fronteiras do trabalho político das esferas governamentais. Em tese, isso permite dizer que a atividade de propaganda não deve se constituir como central na ação política da administração pública, mas que, em virtude do princípio da publicidade dos atos de governo e do direito do cidadão à informação, ela constitui-se como lugar de mediação na configuração do espaço público ${ }^{1}$ paraense. De modo geral, no contexto particular da política de Estado brasileira, recorre-se ao campo da propaganda como lugar de ações especializadas, em que se trabalha a apresentação do dizer por meio de técnicas que visam ao convencimento do público sobre conteúdos vinculados aos mais diversos setores da sociedade.

Para asseverar o reconhecimento das fronteiras da propaganda pelas esferas da gestão pública sob a orientação de partidos políticos específicos, corroborando a percepção da intersecção entre dois campos discursivos com finalidades 
sociais distintas, observa-se no excerto a seguir a circularidade conferida à definição de serviços de publicidade no registro discursivo político materializado na Lei no 12.232 , em análise:

\section{(2) Lei no 12.232}

Art. $2^{\circ}$ Considera-se serviços de publicidade o conjunto de atividades realizadas integradamente que tenham por objetivo o estudo, $o$ planejamento, a conceituação, a concepção, a criação, a execução interna, a intermediação e a supervisão da execução interna e a distribuição da publicidade em veículos e demais meio de divulgação, com o objetivo de promover a venda de bens e serviços de qualquer natureza, difundir ideia e informar o público em geral (BRASIL, 2010, p. 1).

A presença do Outro discursivo da propaganda, traduzido nas linhas oficias citadas, demonstra a delimitação recíproca entre identidades discursivas situadas em campos diferentes que concorrem em uma perspectiva de aliança. Ao que tudo indica, os processos da propaganda de governo efetivam um espaço comum de enunciação submetido a distintas grades semânticas responsáveis pela configuração da cena de enunciação dos textos aí produzidos.

Ao analisar a cena englobante da propaganda do governo do Pará, considerando-se sua relação com uma memória discursiva político-midiática para comprovar seu lugar de inscrição social, é imprescindível considerar o estatuto dos enunciadores em razão das condições de emprego dos anúncios oficiais veiculados pelos diversos suportes midiáticos atuais. Assim, além de apontar especificidades que limitam as ações da propaganda em relação à prática política de Estado, os sentidos da Lei $\mathrm{n}^{\circ} 12.232$ indicam o nível de qualificação da comunidade discursiva que se encontra na posição de produtor dos enunciados.

Nesse sentido, os dois trechos dessa lei citados a seguir alargam as percepções em torno do contexto acional de projeção dos anúncios de propaganda oficial. Em:

Art. $4^{\circ}$ Os serviços de publicidade [...] serão contratados em agências de propaganda cujas atividades sejam disciplinadas pela Lei 4.680 [...] e que tenham obtido certificado de qualificação técnica de funcionamento (BRASIL, 2010, p. 1).

Considerada a especificidade dos serviços de publicidade, recorre-se no próprio texto à dimensão profissional dos sujeitos que dão corpo ao fazer especializado das agências de propaganda.

Já no parágrafo $1^{\circ}$ do artigo $4^{\circ}$, indica-se de modo mais apropriado a autonomia técnica desse setor contratado por meio de parecer de conselho que valida o funcionamento das agências por meio de mecanismos de autorregulação:

(3) Lei no 12.232

$\S 1^{\circ} \mathrm{O}$ certificado de qualificação técnica de funcionamento [...] poderá ser obtido perante Conselho Executivo das Normas-Padrão - CENP, entidade sem fins lucrativos, integrado e gerido por entidades nacionais que representam veículos, anunciantes e agências [...] legalmente reconhecida como fiscalizadora e certificadora das condições técnicas das agências de propaganda (BRASIL, 2010, p. 1).

Evoca-se, implicitamente, o processo de qualificação relacionado à competência de comunicação nas práticas de 
propaganda, que deve obrigatoriamente ser respeitado pelos órgãos oficiais. Tal imperativo legal assevera o caráter interdependente das práticas da propaganda no espaço público brasileiro, ao referir-se a um corpo de práticas com suas próprias rotinas.

Observa-se que a voz oficial expressa pela Lei $\mathrm{n}^{\circ} 12.232$ aponta para o estatuto dos enunciadores autorizados a trabalhar legitimamente na produção da massa textual sob o rótulo de propaganda oficial. Dadas essas primeiras impressões de ordem discursiva, entende-se que a conjugação do mundo da propaganda no cenário da administração pública induz à percepção de que a cena englobante da propaganda oficial é condicionada por um quadro institucional "ligado a competências técnicas com finalidades controladas [cuja] legitimação passa em boa parte pela aquisição de diplomas" (MAINGUENEAU, 2008a, p. 132), descartando-se o fechamento da cena englobante que articula a produção e recepção dos anúncios de governo a uma restrição condicionada apenas pelos sentidos do campo político, para fazer valer a percepção de uma cena englobante que projeta também o contexto acional da propaganda como práxis de comunicação autonomizada.

O sentido imposto pelo dispositivo da cena de enunciação conforma-se com as determinações de zonas de saberes, crenças e poderes que constituem o espaço social. As condições efetivas de produção, circulação e leitura dos textos a partir de sua inscrição sociodiscursiva estabelecem-se em consonância com o contexto acional do discurso que confere o seu estatuto pragmático. A cena englobante, portanto, decorre de uma competência interdiscursiva singular que desenha o grafo de seu espaço documental bem como define o estatuto necessário para se enunciar legitimamente e prever a leitura dos textos, trabalhando, neste sentido, sobre as bases do que Bakhtin (1997) define como instância de compreensão responsiva.

Para assegurar a validade desse percurso de verificação da cena englobante que caracteriza os textos da propaganda do estado do Pará, recorre-se aos textos da Lei no ${ }^{\circ}$.680, de 1965, e das normas-padrão da atividade publicitária, de 1998, que, associados legitimamente ao campo da comunicação midiática, colaboram para o delineamento da massa documental pertinente à posição enunciativa das práticas da propaganda em geral.

Assim sendo, na Lei no ${ }^{\circ} .680$, constata-se aspectos inerentes à qualificação profissional exigida para conduzir o processo de enunciação no contexto das referidas práticas:

\section{(4) Lei no 4.680}

Art. $1^{\circ}$ São publicitários aqueles que, em caráter regular e permanente, exerçam funções de natureza técnica da especialidade, nas Agências de Propaganda, nos veículos de divulgação, ou em quaisquer empresas nas quais se produza propaganda. [...] 
(5) Lei no 4.680

Art. $8^{\circ}[\ldots]$

Parágrafo único. Para o citado registro [registro profissional], o Serviço de Identificação Profissional do Ministério do Trabalho exigirá os seguintes documentos:

1 - diploma de uma escola ou curso de propaganda;

2 - ou atestado de frequência, na qualidade de estudante;

3 - ou, ainda, atestado do empregador (BRASIL, 1965, p. 1).

Observa-se, nesses trechos, o reconhecimento social de uma coletividade de enunciadores que se distingue por um posicionamento especializado. Coletividade sob a qual se impõem regularidades da memória discursiva, que instaura a práxis de propaganda. Aceitando-se, de modo radical, que as condições de emprego dos textos em uma prática discursiva estabelecem cenas de enunciação, pode-se compreender que o estatuto dos enunciadores das práticas de propaganda incide no modo de interpelação dos sujeitos pelos anúncios de governo, condicionando o contexto acional de seus enunciados, mesmo que, conforme Charaudeau e Maingueneau (2012), a identidade enunciativa dessas práticas seja de fraca consistência doutrinal. Assim, induzido pela grade semântica que regula a prática de comunicação de sua comunidade, o profissional da propaganda, ao atuar na produção dos anúncios-filmes de governo, por exemplo, investe deliberadamente na construção de cenografias para persuadir ou convencer o cidadão-espectador acerca das ações positivas do governo.
Verifica-se, entretanto, por essa mesma grade semântica, a imposição de um estatuto, conforme Charaudeau (2013b), cujo dizer não possui um compromisso com o processo de veridição, mas com exposição atraente de uma realidade. Em outras palavras, trata-se de um estatuto de enunciador voltado à criação de expectativa e de desejo em sua instância de recepção por meio de suas práticas linguageiras, como assevera Charaudeau (2013b). Logo, ao definirem seu estatuto de enunciação, os enunciadores que produzem as peças de propaganda inscrevem-se, e com eles seus enunciatários, na mesma posição social: o espaço de persuasão político-ideológica do governo do estado do Pará, em que se adota uma vocalidade específica como modelo de enunciação.

As normas-padrão, por seu turno, oferecem indícios para asseverar a circularidade das atividades de propaganda enquanto zona de produção discursiva, podendo, inclusive, ser alinhada à visão de Maingueneau (2010), segundo a qual se trataria de uma realidade que levanta problemas específicos por infiltrar-se em qualquer zona do universo discursivo, captando-a ou subvertendo-a. Trata-se de um documento que revela uma autopercepção das fronteiras das atividades de propaganda pelas entidades ${ }^{2}$ implicadas na construção do espaço midiático brasileiro.

Além disso, nas Normas-padrão da atividade publicitária, documento assinado por representantes de anunciantes, 
de agências e de veículos de comunicação, definem-se aspectos do relacionamento comercial e profissional do setor específico da propaganda com os demais setores da sociedade. $\mathrm{O}$ documento recupera as principais definições que esboçam o fazer profissional da propaganda: publicidade ou propaganda, anunciante ou cliente, agência de propaganda, veículo de comunicação, agenciador, balcão de anúncios, etc. Logo, com base nos sentidos atribuídos a esses termos pelos sujeitos envolvidos nas atividades de propaganda, são instruídos os processos relacionais com os demais setores de atividades da sociedade.

Esse documento serve de apoio para falar não apenas a respeito da circularidade do setor de propaganda, mas também como base para apontar a possibilidade de sua inflexão nas esferas da administração pública e seu consequente desdobramento na cena englobante dos enunciados da propaganda oficial. Os excertos a seguir ilustram a percepção do setor de propaganda como lugar de organização globalizante em contínua interação no espaço público:

(6) Normas-padrão da atividade publicitária 2.1 As relações entre Agências, Anunciantes e Veículos são, a um só tempo, de natureza profissional, comercial e têm como pressuposto a necessidade de alcance da excelência técnica por meio da qualificação profissional e da diminuição dos custos de transação entre si, observados os princípios deste instrumento, a ética e as boas práticas de mercado, incentivando a plena concorrência em cada um desses segmentos (CONSELHO EXECUTIVO DAS NORMAS-PADRÃO, 2008, p. 6, grifo nosso).
Nesse trecho, destaca-se a interdependência dos agrupamentos de indivíduos que se voltam à finalidade específica de seduzir determinado público-alvo baseado nos estereótipos sociais nos quais ele se move. Decorre disso a projeção dos modos de emprego dos textos que fundam uma prática discursiva assentada sobre a qualificação profissional dos enunciadores, como se vê destacado no excerto. Nota-se, desse modo, a veemência de uma competência interdiscursiva que permite instanciar o trajeto do sentido entre produção e leitura, ao criar condições para que se possa reconhecer ou determinar em que tipo de discurso os anúncios da propaganda de governo podem estar articulados.

Corrobora-se, a partir das inferências das normas-padrão, o esboço de uma competência interdiscursiva midiática que engendra a cena englobante da propaganda de governo, pois se depreende, com base nos serviços apontados no trecho das normas-padrão citado a seguir, as ações linguageiras (entre as quais se podem destacar: (i) o estudo e difusão de conceito, ideia, marca, produto ou serviço e (ii) a elaboração e execução do plano publicitário) que fazem passar a comunicação das ações de governo pelo filtro dos imaginários característicos da instância enunciativa, correspondente ao sujeito enunciador e ao sujeito enunciatário. Considerando-se o elenco de serviços que podem ser executados pelos profissionais da propaganda, fica claro tratar-se de um conjunto de práticas especializadas, cuja 
natureza se distingue no espaço público "fragmentado em diferentes espaços que se entrecruzam e não respondem às mesmas finalidades" (CHARAUDEAU, 2013a, p. 31).

(7) Normas-Padrão da Atividade Publicitária

3.1 Toda Agência, habilitada e certificada em conformidade com o item 2.5 e subitens destas Normas-Padrão, deve estar capacitada a prestar a seu cliente os seguintes serviços, além de outros que constituam seu desdobramento natural ou que lhes sejam complementares, agindo por ordem e conta do Cliente/Anunciante:

3.1.1 Estudo do conceito, ideia, marca, produto ou serviço a difundir, incluindo a identificação e análise de suas vantagens e desvantagens absolutas e relativas aos seus públicos e, quando for o caso, ao seu mercado e à sua concorrência;

3.1.2 Identificação e análise dos públicos e/ ou do mercado onde o conceito, ideia, marca, produto ou serviço encontre melhor possibilidade de assimilação;

3.1.3 Identificação e análise das ideias, marcas, produtos ou serviços concorrentes; 3.1.4 Exame do sistema de distribuição e comercialização, incluindo a identificação e análise das suas vantagens e desvantagens absolutas e relativas ao mercado e à concorrência;

3.1.5 Elaboração do plano publicitário, incluindo a concepção das mensagens e peças (Criação) e o estudo dos meios e Veículos que, segundo técnicas adequadas, assegurem a melhor cobertura dos públicos e/ou dos mercados objetivados (planejamento de Mídia);

3.1.6 Execução do plano publicitário, incluindo orçamento e realização das peças publicitárias (Produção) e a compra, distribuição e controle da publicidade nos Veículos contratados (execução de Mídia), e o no pagamento das faturas (CONSELHO EXECUTIVO DAS NORMAS-PADRÃO, 2008, p. 8, grifo nosso).
Nesse excerto, é possível compreender que tal zona de produção de sentidos evidencia uma competência que integra um estatuto particular para enunciar e um conjunto de procedimentos técnicos pelos quais é possível proferir a palavra que interpela e convida o outro a inscrever-se discursivamente por meio de uma cena englobante de propaganda. Assim, observa-se a imbricação entre uma comunidade especializada e uma textualidade específica na constituição da atividade de propaganda governamental. Assevera-se, desse modo, a percepção de uma competência interdiscursiva que dá condições para a projeção de uma cena englobante de propaganda, seguindo nisso a visão de Foucault (2008), segundo a qual uma fala especializada não pode vir de qualquer um, posto que sua própria existência não é dissociável de sujeitos, definidos estatuariamente, que têm o direito de articulá-la.

Considerando-se a descrição e a interpretação desenvolvidas até aqui, em que se evidenciam certos princípios de propaganda na configuração da cena englobante que articula os anúncios de governo, cabe agora observar a projeção das práticas políticas nas condições de emprego de tal materialidade simbólica. Pretende-se, com esse movimento analítico, apontar para o fato de que as condições de emprego dos textos da propaganda de governo, de um modo geral, ganham sentido a partir da intersecção entre o saber-fazer da propaganda e o saber-fazer da política institucional, 
forjando um lugar de enunciação comum, no qual se pode verificar, por exemplo, o funcionamento discursivo da propaganda de governo do estado do Pará sob a gestão do PSDB.

Antes de delinear, no entanto, a projeção de uma cena englobante política com contornos próprios das noções da socialdemocracia, é imprescindível ter em vista a perspectiva de prática discursiva, como proposto por Maingueneau (2008a), para frequentar determinada superfície textual, diminuindo as margens de equívoco.

\section{Delimitações discursivas das práticas político-partidárias}

Tanto as práticas de propaganda quanto as práticas político-partidárias que convergem para a estrutura administrativa do governo de Estado implicam um desenho organizacional com uma dêixis própria, isto é, uma estrutura e um funcionamento institucional situados em um tempo e lugar discursivo específico, um quadro organizacional que, mediante a semântica global pela qual os planos da discursividade ganham coesão, desdobra-se no processo de textualização dos discursos, incidindo em uma cena englobante político-midiática singular. Se a cena englobante corresponde à vertente pragmática do discurso em decorrência de uma competência que permite ao sujeito determinar a que títu- lo um discurso o interpela, confirma-se por extensão que:

[...] os enunciadores [definidos seu estatuto e modo de enunciação] inscrevem-se, e com eles seus enunciatários, numa certa posição social (MAINGUENEAU, 2008a, p. 122).

Por conseguinte, para dar continuidade à análise dessa cena enunciativa, recorre-se ao programa partidário do PSDB para asseverar o caráter político da coprojeção da cena englobante nos anúncios oficiais.

Para mensurar a cena englobante política por meio da qual os anúncios do governo do estado do Pará são produzidos e lidos, é necessário ter presente o posicionamento partidário que se expandiu nas estruturas de tal esfera de governo no período correspondente ao recorte operacionalizado nesta pesquisa. Trata-se de um posicionamento traduzido em termos de objetivos no seio de uma agenda partidária que se atualiza nos domínios da máquina pública de estado, movimento que gera o desdobramento de uma cena englobante capaz de induzir sentidos de ordem política, projetando uma imagem de governo e de partido, simultaneamente.

É possível ir além na descrição de tal cena, ao se considerar a correspondência desse movimento a uma competência político-partidária que se coaduna com a competência das comunidades dos profissionais da propaganda para conjurar o dizível, o dito e o não-dito, no espaço destinado à enunciação oficial com finalidades persuasivas por meio da espetacularização das ações da máquina 
de governo do Pará, executadas sob a perspectiva ideológica do PSDB. Nesse sentido, para as instituições paraenses (governo e partido) representativas do campo discursivo político, considera-se igualmente o estatuto de seus enunciadores e seu modo de enunciação que incidem nas cenas de enunciação da propaganda do governo do estado do Pará.

Para atestar a veemência dessa competência política implicada na construção da cena englobante de cada anúncio de propaganda oficial que são postos para circular da posição social da administração estatal, observe-se, no programa partidário do partido, a inscrição do PSDB no cenário político, inicialmente, no quadro dos partidos de oposição, almejando sua efetiva participação na vida parlamentar e executiva do país:

\section{(8) Programa partidário do PSDB}

Nascido na oposição - longe das benesses oficiais, mas perto do pulsar das ruas,$- \underline{0}$ PSDB participou do governo Itamar Franco e chegou à presidência com Fernando Henrique Cardoso em 1995, constituindo o núcleo de seu ministério e de sua base no Congresso. De volta à oposição no plano federal desde 2003, manteve-se à frente do governo de vários estados e centenas de municípios. [...]. Foi e continua a ser, desse modo, uma força decisiva para o funcionamento da democracia e a definição dos rumos do Brasil. No governo, o PSDB soube consolidar as instituições democráticas; na oposição, sabe zelar por elas e lutará sempre para que não se amesquinhem (PARTIDO DA SOCIAL DEMOCRACIA BRASILEIRA, 2007, p. 1, grifo nosso).

Do ponto de vista histórico, esse excerto sinaliza a emergência de um quadro institucional distinto no conjunto dos demais partidos que disputam a validade dos sentidos no campo discursivo político nacional. Observa-se, então, a fronteirização tanto de uma prática discursiva quanto da competência que lhe dá corpo, configurando um lugar de subjetivação enunciativa em nome de um ideário, um lugar de filiação discursiva que permite "a aparição, no campo da palavra, de uma população enunciativa distinta" (MAINGUENEAU, 2008a, p. 130).

Ao se indicar por meio do conceito de prática discursiva a existência de sujeitos inscritos na posição enunciativa do PSDB, indica-se igualmente um estatuto para enunciar, um conjunto de ideias aceitáveis em suas grades semânticas. Sujeitos esses identificados com um funcionamento institucional que, além de suas práticas de comunicação política nos diversos segmentos da administração pública, possuem reguladas suas relações humanas igualmente no interior desse partido.

Diante dessa conjuntura, verifica-se que aquilo que se diz no discurso político-partidário do PSDB, e que se reproduz nas esferas administrativas de governo por meio da opacidade da língua, refrata-se na constituição da cena de propaganda que se pode classificar como oficial.

Considerando-se as temáticas abordadas nos anúncios de propaganda oficial, observa-se a persistência de temas caros a uma visão vinculada não apenas ao ideário aceito pelo PSDB, mas à memória que remonta sentidos de um lugar discursivo mais amplo, em que a própria enunciação desse partido pretende estar inscrita: socialismo, social democracia e, 
mais recentemente, a terceira via. Deste modo, a filiação a uma perspectiva ideológica moderada de centro-esquerda, calcada nos pressupostos da social democracia em uma espécie de revisão das bases do socialismo tradicional, pode ser evidenciada nos seguintes excertos do Programa partidário do PSDB:

(9) Programa partidário do PSDB

A liderança emergente do PSDB mudou a agenda política nacional depois de 1994 . Não por capricho ideológico, mas porque entendeu que era preciso romper amarras econômicas que impediam o país de avançar na distribuição de renda e na justiça social. A nova agenda tem, por isso, uma marca claramente socialdemocrática. Mais mercado, mais inserção na economia global, sim. Mas sobretudo mais políticas públicas de combate à pobreza e às desigualdades; mais e melhores serviços sociais básicos com acesso universal (para todos) (2007, p. 3, grifo nosso).

\section{(10) Programa partidário do PSDB}

Porque, se crescer não implica necessariamente em fazer justiça social, a recíproca não é verdadeira: ainda não se viu país que tenha conseguido promover justiça social em larga escala com baixo crescimento econômico (2007, p. 7, grifo nosso).

Indicadas as bases ideológicas que condicionam a emergência de tal partido na conjuntura política brasileira, é possível delinear um estatuto para os enunciadores partidários que, por ocasião de sua entrada na administração púbica, encontram-se implicados na construção das cenas da propaganda oficial com vistas a solidificar a imagem de um modelo de Estado perante a sociedade e a opinião pública, a partir de uma visão moderada, "conjugando a necessidade proeminente de desenvolvimento econômico com a necessidade social de repartição das riquezas produzidas" (CIGNACHI, 2012, p. 123).

Pode-se verificar, portanto, que para se constituir como enunciador nesse quadro discursivo é necessário posicionar-se favoravelmente às lutas em favor da democracia, haja vista que seus fundadores "estiveram na linha de frente da resistência à ditadura" (PARTIDO DA SOCIAL DEMOCRACIA BRASILEIRA, 2007, p. 1), animados pela perspectiva democrática instaurada na Constituição de 1988.

A esse estatuto de enunciador engajado em lutas pela instauração e manutenção do regime democrático associam-se outras qualidades definidas por seus posicionamentos no espectro político. Além disso, o discurso político do PSDB supõe um enunciador experiente que se apoia em saberes técnicos para dar consecução aos objetivos econômicos e sociais de sua agenda partidária. Para ilustrar essa percepção, observam-se a seguir os indicativos da qualificação dos enunciadores que dão base para a sustentação de um modo de enunciação que regula a prática da comunicação dessa instituição partidária:

\section{(11) Programa partidário do PSDB}

Para ajudar a vencê-lo, não faltam ao PSDB dois requisitos fundamentais: competência para manejar com segurança os instrumentos modernos de política econômica e social; e determinação para levar adiante as mudanças necessárias para abrir cada vez mais o estado à participação e às demandas populares (PARTIDO DA SOCIAL DEMOCRACIA BRASILEIRA, 2007, p. 7, grifo nosso). 
(12) Programa partidário do PSDB

Porque temos firmemente enraizado na formação do PSDB o sentido republicano dos limites entre interesse nacional e popular e interesses partidários ou pessoais, soubemos e saberemos aproveitar no governo os melhores talentos do serviço público, da universidade e do setor privado, independentemente de filiação partidária (PARTIDO DA SOCIAL DEMOCRACIA BRASILEIRA, 2007, p. 8, grifo nosso).

A apreensão de um estatuto de enunciador específico que incide sobre a cena englobante da materialidade em análise encontra sustentação na análise de Miqueletti (2002) sobre o "discurso tucano". Para embasar sua descrição do ethos discursivo do então presidenciável Fernando Henrique Cardoso, essa autora, embora indique uma filiação do candidato à memória da direita ${ }^{3}$ política, evidencia um estatuto de representante político típico que atende o que é necessário para poder enunciar:

[...] a condição intelectual, de homem de cultura, marca a diferença no cenário político, onde é recebida como força transformadora: mudar o mundo com as ideias da própria cabeça (MIQUELETTI, 2002, p. 59, grifo da autora).

As ponderações em torno do Plano Real são um exemplo que demonstra a imagem construída em torno do tucano autorizado a tomar a palavra na ação política. Conforme Persson (2010), a vitória nas urnas do PDSB no pleito à presidência de 1994 não seria consequência de seu viés socialdemocrata, "mas [do] Plano Real, produto concebido por uns poucos economistas do PSDB, todos com pós-graduação em ilustres univer- sidades americanas" (FRANCO, 2002 apud PERSSON, 2010, p. 96).

A perspectiva de difusão e leitura dos enunciados é outro fator que permite conferir maior circularidade à cena englobante dos anúncios oficiais do governo do estado do Pará pelo viés político, que se constitui sob uma competência que permite a interpelação e o reconhecimento de lugares discursivos. Mediante essa perspectiva do emprego dos enunciados, constrói-se uma expectativa em torno do coenunciador, aquele que efetivamente se encontra na posição responsiva do outro e é capaz de determinar a que título um discurso o interpela. Posto isso, é possível chegar à definição "de um público, indissociável de um estatuto semântico que o discurso se atribui" (MAINGUENEAU, 2008a, p. 134), confirmando a premissa de que:

[...] os enunciadores [definem] seu 'estatuto' e seu 'modo de enunciação', inscrevendo-se, e com eles seus enunciatários, numa certa posição social (MAINGUENEAU, 2008a, p. 122).

Assim sendo, o "discurso tucano" seguindo a classificação de Miqueletti (2002) para o corpo de prática discursiva do PSDB - prevê uma instância de compreensão responsiva a ser interpelada como cidadão, como se pode observar no programa partidário do PSDB. Mais especificamente, supõe a presença responsiva de um cidadão que se conforma às expectativas do partido e sua consequente filiação ideológica ao ideário da social democracia, que, conforme Persson (2010), tende a implementar 
o Estado de bem-estar social (welfare state) por meio de uma conciliação entre o socialismo moderno e o capitalismo.

Nesse prospecto, o que se visa é:

[...] avançar na transformação do sistema produtivo, de modo a torná-lo mais favorável aos trabalhadores (não apenas o operariado fabril) e excluídos, que formam sua base eleitoral prioritária (REIS, 2012, p. 323).

Sem necessariamente passar pela revolução proletária, como defende o socialismo mais conservador (entidades comunistas ou marxista-leninistas), e sim pela via representativa e parlamentar com o intuito de tornar o sistema capitalista mais equânime, como se infere de Persson (2010). Essa visão flexível da socialdemocracia permite que a instância responsiva idealizada pelo registro discursivo do PSDB assuma status de cidadão caracterizado pelo consumo, pela tributação, pelas necessidades sociais e pela participação.

\section{(13) Programa partidário do PSDB}

[...] trabalhamos para que as empresas privadas, com regras claras, atendam ao interesse público, trazendo prosperidade ao país e satisfação ao consumidor-cidadão (PARTIDO DA SOCIAL DEMOCRACIA BRASILEIRA, 2007, p. 11, grifo nosso).

(14) Programa partidário do PSDB

[...] retomaremos e levaremos adiante as difíceis tarefas de modernização do estado brasileiro. Com tranquilidade, dialogando e buscando consenso com os diferentes setores interessados do próprio estado e da sociedade. Mas sem recuo nem vacilação diante de quem teimar em sobrepor vantagens corporativas ao atendimento devido ao cidadão-contribuinte, principalmente os mais pobres e que mais necessitam da ação do estado (2007, p. 8, grifo nosso).

\section{(15) Programa partidário do PSDB}

A grande novidade política do Brasil nestes vinte anos é a entrada em cena de um personagem: o cidadão informado. Este não quer soluções apenas. Quer participação (2007, p. 22 , grifo nosso).

Deusdará e Rocha (2008, p. 56), ao frequentarem um corpus de textos escolares utilizando a noção de cenas de enunciação, asseveram que a cena englobante define a relação entre os parceiros na comunicação. Identificar de um ponto de vista analítico a cena englobante de dada materialidade discursiva é apontar o processo de interpelação do sujeito (na posição de quem produz e de quem lê). Nesse sentido, pode-se considerar que o "discurso tucano" estabelece um lugar de enunciador que deve necessariamente apresentar-se com ares de intelectualidade, ousadia e modernidade, e, inseridos na administração pública, seu dizer ganha status de oficialidade e autoridade diante de um público do qual não mais se espera apenas um retorno eleitoral, mas o reconhecimento de si enquanto instância de mando político por uma instância cidadã que deva supostamente aspirar ao mesmo ideário e, por isso, elegeu seu quadro partidário.

Corrobora-se aqui a visão de Bobbio (1998) de que a situação dos sujeitos inscritos na comunicação política pertence à categoria do poder do homem sobre outro homem, que no caso das democracias modernas, expressa-se na relação entre Estado e cidadãos. Desse modo, observa-se na constituição da cena englobante dos anúncios de propaganda oficial do 
Pará o reflexo da visão moderna de Estado civil, político e não anárquico,

[...] que ocorre quando os indivíduos renunciam ao direito de usar cada um a própria força [...], para confiar a um único corpo, que doravante será o único autorizado a usar a força contra eles (BOBBIO, 1998, p. 956).

Pode-se dizer que a instância de enunciação exigida pela cena englobante política da propaganda de governo do estado do Pará supõe necessariamente um cidadão eleito democraticamente dirigindo-se a outros cidadãos.

Diante do percurso de constituição da cena englobante dos anúncios do governo e do trajeto dos sentidos no cenário político-midiático do Pará, verifica-se que o emprego de tal materialidade encontra-se tensionado por duas competências interdiscursivas que se interconectam na conjuntura da sociedade atual, estabelecendo o espaço de regularidades enunciativas conhecido familiarmente como propaganda do governo do estado do Pará.

No sentido de corroborar as evidências de tais competências associadas, cabe destacar que desde as primeiras leituras do corpus, relacionando-o à noção de prática discursiva (MAINGUENEAU, 2008a), revelou-se a presença de duas comunidades de enunciadores com rotinas institucionais diferentes, associadas com uma finalidade específica no espaço social. Projetada essa noção na leitura do contexto acional em que os anúncios foram empregados, pode-se dizer que "homem" e "enunciado" são indissociá- veis: olha-se para o "enunciado" e se vê o "homem", suas crenças e valores.

De modo geral, a partir da descrição da cena englobante dos anúncios analisados em meio a suas condições de emprego, foi possível visualizar com clareza a institucionalização de um dispositivo de fala tensionado entre a ação política e a atividade de propaganda, ou seja, de uma cena de enunciação híbrida que se desenvolve progressivamente para validar os efeitos de sentido pretendidos pelo corpo enunciativo que gerencia o governo do Estado.

Esse tipo de funcionamento discursivo que se desdobra efetivamente por meio de uma cena englobante híbrida ganhou espaço recentemente na reflexão de Maingueneau (2015). Em recente publicação, esse autor problematiza a possibilidade de pertencimento simultâneo dos textos a distintos campos de discurso, asseverando que "[...] um texto a partir de sua origem, pode até participar de duas cenas englobantes ao mesmo tempo" (MAINGUENEAU, 2015, p. 120). Assim, a sistematização, a descrição e a interpretação dos dados deste estudo confirmam essa nova percepção da cena englobante enquanto possibilidade que se desdobra de acordo com as restrições de discursos postos em relação.

No caso da superfície simbólica de propaganda de governo do estado do Pará, a cena englobante imprime sentidos de ordem cidadã condicionada pelo jogo democrático e da ordem da espetacularização imposta pela mídia. Essa 
superfície textual político-midiática, observada sua heterogeneidade constitutiva, inscreve-se em um posicionamento especializado que visa deliberadamente seduzir por meio dos princípios de propaganda, assim como se inscreve em um ideário partidário que objetiva implementar um modelo específico de Estado. Assim, no contexto acional instaurado pela propaganda do governo do estado do Pará, seus enunciatários são tomados como cidadãos imersos no espaço público do debate político, mas ao mesmo tempo são tomados como espectadores midiáticos de fatos sociais espetacularizados para a garantia de uma adesão massiva.

\section{Considerações finais}

A análise da cena englobante da propaganda do estado do Pará revelou um espaço discursivo dinâmico cujo funcionamento resulta da interconexão de sentidos advindos de campos discursivos com funções sociais distintas, caracterizando uma prática discursiva híbrida. A análise das materialidades simbólicas inscritas na conjuntura político-midiática do Pará revela a validade do conceito de prática discursiva, segundo proposição de Maingueneau (2008a). Frequentar dados utilizando o conceito de prática discursiva, nesses termos, é manter sempre presente a relação irreversível entre uma superfície simbólica e uma comunidade de enunciadores. Mais: pensar os textos em análise com base nesse conceito "porta de entrada" é observar sentidos que definem espaços, dadas suas regularidades. Assim, pode-se falar apropriadamente da cena englobante: o lugar de onde os textos podem ser interpretados em consonância com posicionamentos, instaurando a vertente pragmática do discurso. Logo, para que se pudesse interpretar a cena englobante de tal modalidade de propaganda, fez-se necessário esboçar traços da competência interdiscursiva dos enunciadores aí envolvidos.

A leitura dos sentidos patentes no corpus com vistas a delinear a cena englobante dos textos de propaganda do estado do Pará revelou o contexto acional projetado pelas restrições semânticas dessa prática político-midiática: uma instância de enunciação (sujeito enunciador e sujeito enunciatário) que se erige em decorrência de um modo específico de enunciar. $\mathrm{O}$ discurso aqui não é apenas o conjunto das ideias sustentadas pelos sujeitos implicados em tal prática de comunicação textual, mas a organização de uma complexa estrutura de interpelação que vai desde seu processo de produção até sua recepção.

Elabora-se, desse modo, a cena englobante da propaganda de governo do estado do Pará tensionada entre duas ordens de sentidos que interpelam o sujeito simultaneamente como cidadão e espetador, face à projeção (publicização) dos fatos do governo conforme as coerções semânticas do espetáculo midiático. Conforme Miguel, "a política inclui o espetáculo desde sempre” (1997, p. 67), en- 
tretanto, é na sociedade da comunicação massiva que a propaganda de governo acentua de modo descomunal a exibição sedutora do corpo político, aproximando-a da publicidade comercial: não se trata apenas de apresentar à instância cidadã obras e serviços da ação administrativa, senão criar uma demanda de desejo em torno de estereótipos políticos habilmente manuseados pela propaganda.

A inferência da qualificação e da competência dos enunciadores da propaganda do governo a partir do corpus, cujos sentidos se refratam na constituição de anúncios oficiais do governo do estado do Pará, revela uma prática discursiva assentada sobre a ação de comunidades situadas em distintas zonas de produção discursiva que articula uma cena englobante híbrida, fazendo valer a recente proposição de Maingueneau (2015) sobre a volatilidade e instabilidade do pertencimento de dado gênero de texto a um único campo discursivo, tanto em uma perspectiva diacrônica quanto sincrônica. Dinâmica discursiva pouco estudada, conforme se verificou na revisão bibliográfica deste trabalho. Sendo assim, para os anúncios que se constituem neste espaço de subjetividade, pode-se afirmar que o modo de interpelação evidenciado situa-se em uma perspectiva sincrônica, em decorrência de seu modo de produção e circulação evidenciar um entrecruzamento entre setores da sociedade restrito a uma conjuntura socio-histórica determinada.
The encompassing scene of the political-media discursive practice of Pará state's govern: the constitution of enunciation instances in the official propaganda

\begin{abstract}
This paper aims at exposing the discursive operation of the State Government of Pará advertisements through the description of the overarching scene that articulates the use conditions of advertisements in this politic space between the period of 2011 and 2014. In order to show the way how the senses are processed in this discursive landscape, it is constituted a corpus of file texts that are the basis for the official advertisement practice ordering, in which focus directly on ads conveyed by the Government of Pará under the administration of a center-left party. It is then discussed the overarching scene (MAINGUENEAU, 2008b, 2013, 2015) that projects the actional context of interaction between subjects from the interdiscursive competencies involved in the production of symbolic materiality in a matter. It is argued that the formation of a hybrid communication practice inquiries coenunciator as citizen-spectator.
\end{abstract}

Keywords: Overarching scene. Governmental advertisement. Interdiscursive competence. 


\section{Notas}

1 Utiliza-se, neste trabalho, a concepção de espaço público de acordo com os sentidos propostos por Habermas (1984 apud SOUSA, 2006): espaço democrático em que se formam as opiniões e as decisões políticas por meio do debate e do uso público da razão argumentativa.

2 Implicadas no processo de comunicação propagandista encontram-se as entidades: Associação Brasileira de Anunciantes, Associação Brasileira de Agências de Publicidade, Federação Nacional das Agências de Propaganda, Associação Nacional de Jornais, Associação Nacional de Editores de Revistas, Associação Brasileira de Emissoras de Rádio e Televisão, Associação Brasileira de Telecomunicações por Assinatura e Central de Outdoor.

3 A partir das análises políticas de Reis (2012) e de Persson (2010), pode-se afirmar que o PSDB, dada sua filiação original à vertente reformista e gradualista do socialismo democrático, situa-se à centro-esquerda no prospecto político. Assim, mesmo não participando das lutas operárias que precederam sua fundação e mesmo não tendo base sindical sólida, esse partido permanece identificado com o ideário socialdemocrata, em que se adota uma visão moderada na implantação do socialismo por meio de reformas democráticas sem prescindir dos meios revolucionários previstos pelo socialismo utópico. Posicionamento ideológico que pode ser corroborado pela afirmação no programa partidário do PSDB de princípios característicos de tal concepção política: direito do voto, parlamentarismo, regulação dos mercados, redução dos índices de exclusão social, entre outros.

\section{Referências}

BAKHTIN, Mikhail. Os gêneros do discurso. In: _. Estética da criação verbal. Trad. Maria Ermantina Galvão G. Pereira. São Paulo: Martins Fontes, 1997. p. 161-306.

BOBBIO, Norberto. Política. In: In: MATTEUCCI, Nicola; PASQUINO, Gianfranco (Org.). Dicionário de política. Trad. Carmen C. et al. 11. ed. Brasília: Editora UnB, 1998. 1 v. p. $954-962$.
BRASIL. Lei no 4.680, de 18 de junho de 1965. Dispõe sobre o exercício da profissão de Publicitário e de Agenciador de Propaganda e dá outras providências. Diário Oficial da União, Brasília, Seção 1, p. 1-3, 21 jun. 1965.

. Lei no 12.232 , de 29 de abril de 2010. Dispõe sobre as normas gerais para licitação e contratação pela administração pública de serviços de publicidade prestados por intermédio de agências de propaganda e dá outras providências. Diário Oficial da União, Brasília, Seção 1, n. 81, p. 1-3, 30 abr. 2010.

CHARAUDEAU, Patrick. Discurso das mídias. Trad. Ângela M. S. Corrêa. 2. ed. São Paulo: Contexto, 2013a. 283 p.

Discurso político. Trad. Fabiana Komesu e Dilson F. Da Cruz. 2. ed. São Paulo: Contexto, 2013b. 327 p.

CHARAUDEAU, Patrick; MAINGUENEAU, Dominique. Dicionário de análise do discurso. 3. ed. São Paulo: Contexto, 2012. 555 p.

CIGNACHI, Henrique. A metamorfose dos partidos de origem na classe trabalhadora a partir da socialdemocracia clássica. Aurora, Marília, v. 6, n. 1, p. 123-138, jul./dez. 2012.

CONSELHO EXECUTIVO DAS NORMAS-PADRÃO. Normas-padrão da atividade publicitária. São Paulo: CENP, dez. 2008. 21 p.

DEUSDARÁ, Bruno; ROCHA, Décio. Cenografias do trabalho docente: produção de subjetividade no mural da sala de professores. Intercâmbio, São Paulo, v. XVIII, p. 43-61, 2008.

DUCROT, Oswald. Esboço de uma Teoria Polifônica da Enunciação. In: O dizer e o dito. Campinas: Pontes, 1987. p. 161-218.

FOUCAULT, Michel. A arqueologia do saber. 7. ed. Rio de Janeiro: Forense Universitária, 2008. 236 p.

MAINGUENEAU, Dominique. Análise de textos de comunicação. Trad. Cecília P. de Souza-e-Silva e Décio Rocha. 6. ed. ampl. São Paulo: Cortez, 2013. 304 p. 
. Discurso e análise do discurso. Trad. Sírio Possenti. São Paulo: Parábola, 2015. 192 p.

. Gênese dos discursos. Trad. Sírio Possenti. São Paulo: Parábola, 2008a. 184 p.

. Novas tendências em análise do discurso. 3. ed. Campinas: Pontes, 1997. 198 p.

Situação de enunciação e cena de enunciação em análise do discurso. In: . Doze conceitos em análise do discurso. Trad. Nelson Barros da Costa. São Paulo: Parábola, 2010. p. 199-207.

. Unidades tópicas e não-tópicas. In: . Cenas da enunciação. Trad. Cecília P. de Souza-e-Silva. São Paulo: Parábola, 2008b. p. 9-24.

MIGUEL, Luís Felipe. Em busca da harmonia perdida: mito e discurso político (uma análise a partir da campanha eleitoral brasileira de 1994). 1997. $281 \mathrm{f}$. Tese (Doutorado em Ciências Sociais) - Instituto de Filosofia e Ciências Sociais, Universidade Estadual de Campinas, Campinas, 1997.

MIQUELETTI, Fabiana. Discurso, tom e caráter: uma análise do ethos tucano. 2002. 177 f. Dissertação (Mestrado em Linguística) - Instituto de Estudos da Linguagem, Universidade Estadual de Campinas, Campinas, 2002.

ORLANDI, Eni Puccinelli. Análise de discurso: princípios e procedimentos. 10. ed. Campinas: Pontes, 2012. 100 p.

PARTIDO DA SOCIAL DEMOCRACIA BRASILEIRA. Programa partidário. Brasília: [s. n.], 2007. 24 p.

PERSSON, Luiz Felipe. A social democracia: a construção de um modelo social democrata no Brasil. Conversas e Controvérsias, Porto Alegre, v. 1, n. 1, p. 90-104, 2010.

REGO, Francisco G. Torquator. Marketing político e governamental: um roteiro para campanhas políticas e estratégias de comunicação. São Paulo: Summus, 1985.
REIS, Guilherme Simões. Redefinindo a base teórica para o estudo dos partidos socialdemocratas. Civitas, Porto Alegre, v. 12, n. 2, p. 321-339, 2012.

SOUSA, Jorge Pedro. Conceito e história breve da comunicação em sociedade (comunicação social). In: Elementos de teoria e pesquisa da comunicação e dos media. Porto, PT: BOCC, 2006. p. 127-191. 